\title{
La política colonial en las obras del Inca Garcilaso de la Vega y de Guaman Poma de Ayala ${ }^{1}$
}

\author{
Mercedes SERNA ARNAIZ \\ Universidad de Barcelona
}

\begin{abstract}
RESUMEN
El presente artículo analiza los Comentarios reales e Historia general del Perú, de Garcilaso de la Vega, y la Nueva corónica y buen gobierno, de Guaman Poma de Ayala, teniendo en cuenta las distintas leyes que la corona española promulgó para el buen gobierno de las indias. Esta aproximación permite destacar aquellas partes de ambas crónicas cuya redacción está más íntimamente ligada al devenir de la política colonial durante el siglo XVI.
\end{abstract}

Palabras clave: crónica-política, encomiendas, autonomía indiana, Garcilaso de la Vega, Guaman Poma de Ayala.

The colonial politics in the works of the Inca Garcilaso de la Vega and of Guaman Poma de Ayala

\begin{abstract}
The present article analyzes the Comentarios reales and Historia general del Perú, of Garcilaso de la Vega, and the Nueva corónica y buen gobierno, of Guaman Poma de Ayala, having in counts the different laws that the Spanish crown promulgated for the good government of the indies. This approximation allows to emphasize those parts of both chronicles which draft is tied more intimately on having developed of the colonial politics during the 16 th century.
\end{abstract}

Keywords: Chronicle-Politics, Commissions, Indian autonomy, Garcilaso de la Vega, Guaman Poma de Ayala.

SUMARIO: 1.Introducción. 2. Encomiendas, leyes, cédulas y otras disposiciones generales. 3. Leyes y encomiendas en Perú. Los casos del inca Garcilaso y Guaman Poma de Ayala. 4. Conclusión.

${ }^{1}$ Este estudio se inscribe en el marco del proyecto de investigación, del Ministerio de Ciencia e investigación, Diccionario histórico de la traducción en Hispanoamérica (con código de referencia FFI2009-13326-C02-01). 


\section{Introducción}

Las crónicas de Indias no sólo son fundamentales por las informaciones antropológicas, sociales, culturales, literarias o históricas que ofrecen sobre el Nuevo Mundo sino porque muchas de ellas -textos de Juan de Zumárraga, De Las Casas, Cieza de León, Motolinía, José de Acosta, Garcilaso de la Vega, Hernán Cortés, Guaman Poma de Ayala, Pedro Sancho, Tito Cusi Yupanqui, Francisco López de Jerez o Cervantes de Salazar, entre otros- están vinculadas a los hechos capitales de la justicia colonial en América.

Pereña destaca tres momentos claves de este proceso, con sus tres rupturas consiguientes: en primer lugar, la gran denuncia profética de Montesinos en 1511 con su quiebra con la imposición del Requerimiento y su aplicación abusiva, plasmada en las conquistas mexicanas y peruanas; el segundo momento vendría con la gran reivindicación académica de 1539 del padre Vitoria y su ruptura con la rebeldía de los encomenderos y la falta de adecuación entre la realidad indiana y la utopía vitoriana; el tercero se iniciaría con la decisión por parte de Carlos V, en 1556, de prohibir oficialmente las guerras de conquista, aunque la preponderancia de los intereses económicos provocaría la tercera quiebra de la justicia colonial (Pereña, 1992: 11).

Fueron muchos los cronistas que, en sus respectivas obras, trataron de los problemas surgidos tras la imposición del sistema legislativo español. En muchos casos, además, no fueron meros informantes sino que se definieron por una línea política determinada e incluso, en ocasiones, escribieron sus obras para defenderla. Las crónicas de Indias, en definitiva, fueron un verdadero correlato textual de la conquista militar y religiosa y son documentos fundamentales para una comprensión cabal de la conquista y la colonización. Como indica Zavala, cabe pensar en "la conquista española de América como un antecedente valioso de la presente experiencia internacional y política, aunque no sean idénticas la terminología ni la individualidad histórica en cada caso" (Zavala, 1973: 21).

\section{Encomiendas, leyes, cédulas y otras disposiciones generales}

Las quejas continuas por el abuso de poder y la codicia de Colón y su familia, la venta de esclavos llevada a cabo por el Almirante, desde el inicio del descubrimiento, y la influencia de Cisneros sobre los Reyes Católicos ${ }^{2}$ harán que, por cédula real del 20 de junio de 1500, estos resolvieran a favor de la libertad de los indios, "man-

${ }^{2}$ La esclavitud impuesta a los indios por Colón, de forma arbitraria, y la venta de esclavos que se hizo en Andalucía, por mandato suyo, irritaron a la Reina, según cuenta Oviedo en su Historia general y natural de las Indias. 
dando que los indios que se trajeron de las islas y se vendieron por mandato del Almirante, se pongan en libertad y se restituyan a los países de su naturaleza":

Ya sabéis como por nuestro mandato tenedes en vuestro poder en secuestración e depósito algunos indios, de los que fueron traídos de las Indias e vendidos en esta ciudad a su arzobispado y en otras partes de esta Andalucía, por mandato de nuestro Almirante de las Indias. Los cuales agora Nos mandamos poner en libertad, e habemos mandado al comendador fray Francisco de Bobadilla que los llevase en su poder a las dichas Indias, e faga de ellos lo que le tenemos mandado. Por ende, Nos vos mandamos que luego que esta nuestra Cédula viéredes, le dedes e entreguedes todos los dichos indios que así tenéis en vuestro poder, sin faltar de ellos ninguno por inventario e ante escribano público, e tomad su conocimiento de cómo los recibe de vos; con el cual y con esta nuestra Cédula mandamos que no vos sean pedidos ni demandados otra vez. (Fernández de Navarrete, 1825, II: 246247).

Aunque esta es la disposición principal, hubo muchas otras que decretaron que los indios eran vasallos de la Corona de Castilla y libres, como las de 1501, 1503 o 1507. En la de Granada, del 16 de septiembre de 1501, se recomienda lo siguiente:

Otrosí procuréis como los indios sean bien tratados y puedan andar seguramente por toda la tierra, y ninguno les haga fuerza, ni les roben, ni hagan otro mal ni daño, [...] porque somos informados que algunos cristianos de las dichas islas, especialmente la Española, tienen tomadas a los dichos indios sus mujeres e hijas y otras cosas contra su voluntad.

El incumplimiento de la ley fue severamente castigado. Pero, una vez que los indios fueron declarados libres y vasallos de la Corona, surgieron problemas económicos y de convivencia, si atendemos a las informaciones que al respecto le llegaron a la Reina:

Hobimos mandado (dice la reina Isabel) que los indios [...] fuesen libres y no sujetos a servidumbre: y agora somos informados que, a causa de la mucha libertad que los dichos indios tienen, huyen y se apartan de la conversación y comunidad de los cristianos, por manera que aun queriéndoles pagar sus jornales no quieren y andan vagamundos.

Dada las necesidades económicas de la Corona, el 16 de septiembre de 1501, el Rey y la Reina dieron instrucciones a Nicolás de Ovando para que los indios trabajasen y recibieran a cambio un salario justo:

Ítem: y porque para coger oro y hacer las otras labores que Nos Mandamos hacer, será necesario aprovecharnos del servicio de los indios, que les compeláis a que trabajen en las cosas de Nuestro servicio pagando a cada uno el salario que justa- 
mente os pareciere que debieren de haber según la calidad de la Tierra. (Colección de documentos inéditos, XXXI: 16)

Los repartimientos de indios se legalizaron el 20 de diciembre de 1503, confirmándose el trabajo obligado de los indígenas, aunque se les debía pagar un salario por ser hombres libres. Dicha cédula, dictada en Medina del Campo, informaba de los problemas que había generado la declaración de 1500, por la cual los indios eran libres y por tanto, por su nuevo status, podían huir de los españoles y del trabajo, ni que fuera éste retribuido. Ello imposibilitaba la comunicación y la evangelización. En consecuencia, se aceptaría el trabajo forzoso bajo la vigilancia oficial y la retribución del jornalero sería tasada por el Estado. El sistema de la encomienda, por tanto, resolvía el problema económico y el de la evangelización y beneficiaba a los conquistadores y encomenderos (Zavala, 1973: 16).

Las encomiendas y los repartimientos de indios surgieron, casi al mismo tiempo, en las Antillas, a partir del segundo viaje de Colón, que impuso, entre los años 1495 y 1496, a los vecinos mayores de catorce años de edad, de la isla Española, y a todos los que vivían cerca de las minas, un tributo al Rey. Este consistía en una cantidad de oro fija cada tres meses y los que no vivían cerca de las minas debían entregar una arroba de algodón por persona. Como señala Silvio Zavala, el servicio de los indios en las minas, cuando Bobadilla mandaba en la Española, fue gravado por la Corona con un impuesto de un peso por cada once de rendimiento, a cargo del español beneficiario del trabajo de los indios repartidos. Además, el Rey tuvo indios de repartimiento en sus granjas y minas, a modo de un encomendero mayor (Zavala, 1973: 14). La finalidad del repartimiento, indica Zavala, era llenar las necesidades de mano de obra de las empresas agrícolas y mineras de los colonos y de la Corona. Jurídicamente se caracterizaba por ser un sistema de trabajo forzoso, sin contrato de asalariado. Los indios considerados legalmente esclavos prestaban también sus servicios en los trabajos de la isla, pero sin confundirse con los libres.

Señala Zavala que, a pesar de la insistencia en el principio de la libertad legal del indio repartido, para diferenciarlo jurídicamente del esclavo (este podía ser vendido y carecía del derecho de tener bien), "la distinción no dejaba de ser hasta cierto punto formal, porque unos y otros indios se consumían en los mismos trabajos" (Zavala, 1973: 16).

Gonzalo Fernández de Oviedo o Bartolomé de las Casas ${ }^{3}$ manifestaron lo perjudiciales que fueron los repartimientos y las encomiendas para los indios. Oviedo, en su Historia general y natural de las Indias, anota al respecto:

${ }^{3}$ Bartolomé de las Casas, en su Historia de las Indias, aclara que el Comendador mayor de Alcántara, en 1503, engañó a los Reyes al informarles que "a causa de la libertad que a los indios se había dado, huían y se apartaban de la conversación y comunicación de los cristianos; por manera que, aun queriéndoles pagar sus jornales, no querían trabajar y que 
Dieron asimismo gran causa a la muerte de esta gente, las mudanzas que los gobernadores y repartidores hicieron de estos indios; porque, andando de amo en amo y de señor en señor, y pasando los de un codicioso a otro mayor, todo esto fue unos aparejos y instrumentos evidentes para la total difinición de esta gente, y para que, por las causas que he dicho o por cualquiera de ellas, muriesen los indios. Y llegó a tanto el negocio, que no solamente fueron repartidos los indios a los pobladores, pero también se dieron a caballeros y privados, personas aceptas y que estaban cerca de la persona del Rey Católico, que eran del Consejo Real de Castilla y Indias, y a otros. Cosa, en la verdad, no para sufrirse, porque, aunque eran personas nobles y de buena conciencia, por ventura sus mayordomos y fatores, que acá andaban con sus indios, los hacían trabajar demasiadamente por los disfrutar para los de allá y de acá. Y como eran personeros y ministros de hombres tan favorecidos, aunque mal hiciesen, no los osaban enojar. Por cierto, ningún cristiano habrá envidia de la hacienda que así se allegase. (Oviedo, 1959, XVII: 67).

Las quejas de las órdenes religiosas por las encomiendas, por los repartimientos y por los abusos perpetrados a los indios alcanzarán hasta 1550 , fecha de la celebración de la famosa controversia entre Sepúlveda y Las Casas.

Del sermón de Montesinos surgirán los debates sobre el problema ético de la conquista y sobre los justos títulos o el derecho a la guerra. Como indica PérezBustamante, a principios del siglo XVI se entendía que si las guerras estaban aprobadas por quien tenía el derecho de autorizarlas eran justas y por consiguiente también lo era la conquista (Pérez-Bustamante, 1991: 92).

El sistema de la encomienda aplicado junto con el status de libertad otorgado a los indios creaba un conflicto normativo. Las Leyes de Burgos y de Valladolid, de 1512 y 1513 respectivamente, intentarán remediar en lo posible esta incompatibilidad, al tratar la mayoría de ellas de la protección de los indios. Por dichas leyes se consiguió la limitación de las jornadas de los indios, la vigilancia del pago de salarios y mantenimientos y otras medidas de protección, si bien no se eliminó el trabajo forzoso. Además, en 1513 se impuso el Requerimiento, por el que se informaba a los indios de la existencia y reconocimiento de los títulos pontificios y de la potestad real sobre ellos, a la par que advertía de que en el caso de que tales títulos no se respetaran se les podría hacer la guerra. Este documento tuvo esencialmente dos finalidades: que no recayera toda la responsabilidad de la conquista en los Monar-

andaban vagabundos y que menos los podían haber para los doctrinar y traer a que se convirtiesen a nuestra santa fe católica" (De Las Casas, 1986: 47) Bartolomé de las Casas excusará, seguidamente, a la Reina de haber autorizado las encomiendas y la venta de indios, aduciendo que fue engañada. El dominico desea salvaguardar la fama de la Reina y la muestra víctima de una falsedad. 
cas y conquistadores y que se aplicaran las Bulas pontificias. La práctica del Requerimiento sería abusiva, principalmente en Perú.

Durante todos estos años hubo muchos repartimientos de indios. Según Bartolomé de Las Casas, desde el año 1514 existían repartimientos "por dos vidas"- el punto más conflictivo desde el punto de vista legislativo- y eran la base de la economía antillana. Al no abolirse las encomiendas, a pesar de las leyes, cédulas y disposiciones que se promulgaron para la protección de los indios, la situación para estos fue catastrófica, muy especialmente en las islas descubiertas por Colón. Poseemos una gran cantidad de documentos que abundan en esta trágica realidad. Para paliar la situación se escribieron hacia 1517 muchos memoriales con el fin de que la isla Española se repoblara, como el "Memorial informatorio acerca del modo que se ha tenido en el repartimiento de indios de la isla Española, y lo que conviene proveer para que la tierra se pueble", redactado posiblemente en dicha fecha, puede que por un padre jerónimo, y donde se dice cómo al ser Gobernador Diego Colón, "quitó a muchos los indios, y diolos a sus criados, y a los que eran de su opinión, de do se siguieron muchos daños y discordias" (Colección de documentos inéditos, 1864, I: 248).

A partir de 1518, con la llegada de Carlos V acompañado de los caballeros flamencos, se inicia otra etapa de la encomienda, por cuanto se hace una revisión más profunda de los principios que la sustentaban. Estando la Corte en Barcelona, se celebró una sesión ante Carlos $\mathrm{V}$ en la que, frente a la posición de Las Casas, el obispo de Darién, Juan Quevedo, defendió el principio aristotélico de la servidumbre natural. Según cuenta Bartolomé de Las Casas, en 1519 diversos predicadores intervinieron en el Consejo de Indias y redactaron un texto contrario a la institución de las encomiendas. La provisión del 9 de diciembre de 1518, dictada en Zaragoza por el juez que residía en la isla Española, había mandado "que los indios que tuvieran habilidad vivieran para sí y se quitaran a los encomenderos y que cada indio de más de veinte años pagara al Rey tres pesos y los demás un peso; los caciques que quisieran vivir en los pueblos libres, sin encomiendas, debían solicitarlo del juez".

El 27 de noviembre de 1526 se dictó en Granada otra provisión de don Carlos y doña Juana sobre el buen tratamiento de los indios, que insistía en el cumplimiento de lo que se había establecido en las Leyes de Burgos y de Valladolid (Colección de documentos inéditos, 1864, I: 450 y ss.). En dicha ley se describe, con toda su crudeza y sin ambages, el vergonzoso estado en el que se encontraban los indios a manos de los españoles.

El Emperador, desde Segovia, el 28 de septiembre de 1532, extendería a Cuba la provisión relativa a los pueblos libres. En Roma, el 29 de mayo de $1537,{ }^{4}$ se dicta el breve Pastorale Officium de Pablo III (1534-1549), dirigido al Cardenal Juan Tavera, arzobispo de Toledo, que reconocía la libertad de los indios y excomulgaba a los que les esclavizaban. Asimismo, la "Bula sublimis Deus de Paulo III" (1534-1549),

\footnotetext{
${ }^{4}$ Suess lo data del 29 de junio de 1537.
} 
del 2 de junio de 1537, declaraba a los indios libres y capaces para la fe cristiana, prohibía su reducción a la esclavitud e insistía en su conversión a través de la palabra de Dios y del buen ejemplo. ${ }^{5}$ Por esta época, Francisco de Vitoria, con sus Relecciones, sienta las bases para liberar a los indios de las obligaciones de la política teocrática establecida y, en concreto, del Requerimiento. En este sentido, vale señalar que Francisco de Vitoria fue más lejos que Bartolomé de las Casas en la lucha por los derechos humanos al negar el dominio espiritual y temporal del Papa y de los reyes o emperadores.

\title{
Leyes y encomiendas en Perú. Los casos del inca Garcilaso y Guaman Poma de Ayala
}

Con la conquista de Perú, como señala Pereña (Pereña, 1992: 66), la "teocracia pontificia fue llevada por Pizarro hasta sus últimas consecuencias", originándose en el territorio muchas alteraciones:

\begin{abstract}
Al filo de los acontecimientos del Perú y por incidencia principalmente de las juntas de México, después sobre todo de la bula Sublimis Deus y del breve Pasttorale Oficium de Pablo III, tiene lugar la primera ruptura entre evangelización y conquista. Se aprecia una evolución o cambio en Zumárraga y Quiroga. La polémica sobre la esclavitud y el bautismo de los indios lleva a la contradicción y a una verdadera confusión de opiniones. La experiencia de Jacobo de Tastera en Yucatán y la intervención de Bartolomé de las Casas en los Consejos fuerzan a posiciones más radicalizadas de evangelización pacífica. Hasta el emperador Carlos $\mathrm{V}$ va cediendo a la presión de informes y denuncias llegados a España alrededor de 1538, y que dan como resultado la convocatoria de la primera junta de Valladolid y la promulgación de las leyes de Indias de 1542. (Pereña, 1992: 102)
\end{abstract}

La situación de abuso y tiranía de los conquistadores sobre los indios sería denunciada, prácticamente de forma unánime, por muchos religiosos y cronistas del Perú, como Cieza de León, Agustín de Zárate, Cristóbal de Molina, Polo de Ondegardo, Domingo Santo Tomás, Guaman Poma de Ayala, Garcilaso de la Vega o Acosta, y por los religiosos y cronistas de otros territorios americanos. Pero esta condena no fue mayoritaria en el tema de las encomiendas. De esta manera, algunos cronistas como Las Casas u Oviedo criticaron abiertamente dicho sistema pero otros muchos (Zárate y Ondegardo fueron encomenderos) se pronunciaron a favor o no se manifestaron claramente. Tratándose del Tahuantinsuyo, el indio Guaman Poma de

${ }^{5}$ Sobre dicha bula véase el estudio de Silvio Zavala. Repaso histórico de la Bula Sublimis Deus de Paulo III en defensa de los indios: México, Universidad Iberoamericana, 1991. 
Ayala mantuvo una actitud ambigua, dependiendo del sujeto al que se aplicara, y el mestizo Garcilaso de la Vega lo defendió.

En 1542 se convocó, primero en la ciudad de Valladolid y luego en Barcelona, la junta que representaría el último pleito sobre las encomiendas. Bartolomé de las Casas presentó su petición de eliminar las encomiendas en veinte argumentos. Como resultado, se dictaron las Leyes Nuevas, de 1542, que, como punto principal, abolían las encomiendas. El 4 de junio de 1543 se dictó una declaración que completaba las Leyes Nuevas, ampliándose a los hijos de los conquistadores el derecho de ser preferidos en los corregimientos y oficios para que pudieran recibir algún premio por los servicios prestados por el padre, en el caso del fallecimiento de este. Se dictó, asimismo, que el encomendero viviera en la provincia de sus encomendados y se impusieron las tasaciones de los tributos por parte de las Audiencias de Indias.

Estas ordenanzas se fueron ajustando a los respectivos territorios americanos, pero su implantación produjo tales desórdenes -rebeliones de conquistadores como Gonzalo Pizarro y los Contreras, en Perú y América Central- que hasta algunos religiosos acabaron dudando de su conveniencia. Las distintas posturas que fueron tomando unos y otros guardan relación con la concepción medieval que tienen de la sociedad política.

En 1544 los dominicos de Nueva España se pronunciaron a favor de las encomiendas y de la revocación de las Leyes Nuevas y lo mismo ocurrió con los franciscanos, basándose unos y otros en razones religiosas y militares. Desde el 20 de octubre de 1545, tras la entrevista de los procuradores de la Nueva España con el Emperador, se irían anulando algunos capítulos de las Leyes Nuevas, hasta la derogación de los puntos más conflictivos o radicales. En concreto, el 20 de octubre de 1545, Carlos V dictó la cédula que revocaba el artículo XXX (ley de herencia) y modificaba el XXXIII.

Los historiadores discrepan sobre los verdaderos motivos por los que la Corona implantó y revocó, posteriormente, algunas de las Leyes Nuevas. Impera la idea de que fueron unas ordenanzas de inspiración lascasiana, si bien no comparte el mismo criterio Pérez de Tudela. Este opina que la implantación de las Leyes Nuevas no debe entenderse como un acto de defensa del indígena, sino en el contexto del gobierno político de Indias. La Corona preveía la posibilidad de que la promulgación de las nuevas ordenanzas provocara una gran confusión entre los pobladores de las Indias. Entonces puede decirse que la redacción y la revocación parcial de las Leyes Nuevas demuestran que la política indigenista de la Corona fue planeada esencialmente prestando mayor atención a los conquistadores y colonizadores españoles que a los naturales de Indias (Pérez de Tudela: 1958: 489-492). La promulgación de las Leyes Nuevas podría interpretarse en este sentido, si partimos de la tesis de Pérez de Tudela, como una reafirmación de la Corona ante cualquier intento de autonomía feudal o política de los encomenderos, y su revocación como la derrota de dicha institución. No hay que olvidar, sin embargo, que las actuaciones políticas 
del Imperio, llevadas a cabo con anterioridad a la promulgación de las Leyes Nuevas, se dirigieron en defensa y protección del indio y que en 1556, Carlos V, siguiendo en su línea política, prohibió oficialmente las guerras de conquista. Como indica Pereña, "la nueva política de reconversión inicia un programa novedoso de gobierno colonial. Sus metas y objetivos fueron la rehumanización, la pacificación y la reconciliación" (Pereña, 1992: 11).

Sobre estos años se abandonó la práctica del Requerimiento y en las ordenanzas de Felipe II, de 1573, se sustituyó el término conquista por el de pacificación. En la "Recopilación de las Leyes de Indias", de 1680, se mandó, en la ley 9, título 4, libro III, "que no se pueda hacer, ni se haga la guerra a los indios de ninguna provincia para que reciban la santa fe católica o nos den la obediencia, ni para otro ningún efecto". Silvio Zavala señala que "el régimen español extinguió la institución de las encomiendas", porque en los escritos del movimiento de independencia de las colonias del XIX "se encuentran pocas o ningunas alusiones a encomiendas, y en cambio muchas relativas al tributo personal que los indios pagaban a la Corona, en el cual se habían refundido las antiguas rentas encomendadas" (Zavala, 1973: 255). Cabe decir, en este sentido, que los tributos siguieron manteniéndose tras las guerras de independencia, debido a los grandes gastos que estas habían generado. Como señala Silvio Zavala, "la guerra llegó a ser proscrita legalmente, en términos generales, como instrumento de la penetración religiosa y política española en el Nuevo Mundo" (Zavala, 1973).

En el caso de Perú, la relación de los cronistas con la política colonial está vinculada directamente a la rebelión de Gonzalo Pizarro, que se alzó contra la Corona en junio de 1544. Asimismo, hay que tener en cuenta el caso concreto de la riqueza de la tierra peruana. Alfonso Klauer, en su estudio En las garras del imperio, especifica las cantidades ingentes de plata que se extrajeron del Perú, la explotación y muerte de muchos indios y la desertización del territorio, a la par que arremete contra el "imperio socialista de los incas" que Garcilaso de la Vega dibujó en su crónica.

Algunos cronistas, además, enmendaron sus propias obras (muchas están dedicadas al Rey) modificando sus vinculaciones, posiciones políticas o actuaciones en América con el fin de mantenerse fiel a la Corona. Teodoro Hampe, en un artículo publicado en la revista Mélanges de la Casa Velázquez, defiende, por ejemplo, que, en verdad, Agustín de Zárate, contador y cronista indiano, fue pizarrista, amigo de Gonzalo, y que cambió su versión en su Historia del descubrimiento y conquista del Perú para hacerse antipizarrista y partidario de Blasco Núñez. Zárate era el encargado de examinar la administración y rentas de su Majestad en el rico virreinato del Perú. Su misión, concretamente, consistía en inspeccionar los libros de cuentas fiscales de Perú y Tierra Firme, revisar el trabajo que había realizado con anterioridad Vaca de Castro y controlar que se tributara a la Corona lo estipulado. Zárate, vinculado familiarmente a Polo de Ondegardo, se embarcó con este y otros familiares, y junto con Blasco Núñez, el 3 de noviembre de1543. Como posteriormente hará el inca Garcilaso, criticó la severidad de Blasco Núñez en el cumplimiento de las or- 
denanzas, las cuales, dada su rigidez, no podían aplicarse en las colonias, "porque lo que hacía falta era prodigar premios, regalos, mercedes". ${ }^{6}$ El cronista español, señala Hampe, expresó haber oído que mucha gente se quejaba de la manera de gobernar de Blasco Núñez. Fue el propio Zárate quien tramitó la hoja que hacía gobernador a Gonzalo Pizarro, el 23 de octubre de 1544, al entender que este tenía más poder como líder de los encomenderos que la Real Audiencia. Y no sólo lo apoyó sino que incluso le suministró dinero del Tesoro Público. No estando limpia su hoja de servicios, decidió quedarse en América y designó abogado de la Real Hacienda a su sobrino Polo de Ondegardo, el cual se haría poderoso encomendero. Zárate salió al fin hacia España el 9 de noviembre de 1545. Parece ser que la génesis de su Historia del descubrimiento y conquista del Perú fue una relación que escribió a Carlos V justificando su vuelta a España. Dicha crónica, -fuente principal de las de Garcilaso de la Vega y Guaman Poma de Ayala- fue enmendada en diversas ocasiones por su autor, con el fin de hacerse antipizarrista y fiel a Blasco Núñez.

Si la génesis de la crónica de Zárate se adscribe a la relación que escribió al Rey justificando su vuelta a España y sus actuaciones en el Nuevo Mundo, en la Historia general del Perú, Garcilaso pretenderá, entre otros motivos, defender la memoria de su padre, que fue pizarrista hasta que se pasó de bando del virrey la Gasca. Nacido en el Cuzco (1539-1616), de padre español y madre de presunta prosapia indígena, el inca Garcilaso se proclamará heredero de estas dos tradiciones. Escribió gran parte de la Historia general del Perú ${ }^{7}$ paralelamente a sus Comentarios reales. Ambos libros debían ver la luz como una única obra -como señala el propio autor en el último capítulo de su Historia- aunque finalmente se publicaron de forma separada: los Comentarios reales en 1609 y la Historia general del Perú, tras la muerte del autor, en 1616. La primera parte está escrita en honor a la memoria de su madre y la segunda en honor a la de su padre. Garcilaso analizará en la Historia general del Perú las luchas entre Pizarro y Almagro, la llegada de Blasco Núñez y las acciones de Gonzalo Pizarro, en la línea de Zárate. Garcilaso elogiará a Francisco Pizarro y defenderá las actuaciones de su hermano, Gonzalo, a la vez que arre-

${ }^{6}$ AGI (Archivo General de Indias), justicia, 451, f. 1042. Declaración hecha en Lima, 24-IX-1544. Tomado de Teodoro Hampe

${ }^{7}$ Los estudiosos garcilasistas han trabajado los Comentarios reales y la Historia general del Perú como dos obras de tono, espíritu y finalidad distintas. De la primera se ha destacado su neoplatonismo, estructura mítica y el tono en general indígena, en tanto de la segunda se ha resaltado su realismo y su tono español. La insistencia en separar ambas obras ha hecho que se haya exagerado tanto el neoplatonismo e indigenismo de la primera como el excesivo realismo y españolización de la segunda, dividiendo al propio autor en una dicotomía, indio frente a español, irresoluble. A mi modo de ver, los Comentarios y la Historia deben analizarse como una única obra. Una carta que encontró Miguel Maticorena ${ }^{7}$, fechada en Córdoba, España, confirma que en 1604 la Historia seguía concibiéndose por su autor con el único título de Comentarios reales. 
meterá contra el virrey Blasco Núñez. La crónica garcilasiana, partiendo del esquema de Pereña, se inscribe, por tanto, en ese segundo momento clave de la justicia colonia, con la segunda ruptura que vendría con la rebeldía de los encomenderos y la falta de adecuación entre la realidad indiana y la utopía vitoriana.

El Inca juzgará muy favorablemente la llegada del licenciado Vaca de Castro a Perú. Este partió de España en 1540 y entró en Lima el 7 de agosto de 1542 con el fin de poner paz en las guerras civiles, revisar las encomiendas de Francisco Pizarro, obligar a los encomenderos a contraer legítimo matrimonio, evitar los repartimientos y suprimir impuestos abusivos. Vaca de Castro fue apresado por el que sería su sucesor, Blasco Núñez, al temer este una conspiración por parte de aquel. Según el inca Garcilaso, las leyes que impuso Vaca de Castro eran acordes a las de los reyes incas, unas y otras defendían la paz, el bien común y la doctrina cristiana. "El demonio", ${ }^{8}$ en opinión de Garcilaso, tomó la forma de las Leyes Nuevas "u ordenanzas de Bartolomé de las Casas", leyes excesivamente rigurosas, con jueces tan severos que "el Perú, por el rigor que en él se usó, estuvo tan en canto de perderse y enajenarse de la Corona de España, como por la historia se verá, si la benignidad y blandura del emperador no volviera a restituirlo".

Garcilaso trata sólo los puntos que considera más conflictivos de las Leyes Nuevas: el primero es el de la sucesión o herencia de repartimientos de indios en la esposa o hijos; el segundo punto recoge que no se cargasen a los indios, que no fueran a las minas, que se tasasen los tributos y que se quitasen los indios de servicio; el tercero, que se quitasen las encomiendas y repartimientos de indios a los obispos, monasterios y hospitales y que se quitasen indios a gobernadores, presidentes, corregidores, oidores u oficiales de justicia; por último, que se quitasen indios a todos los encomenderos que se hubieran hallado en las alteraciones ocasionadas entre Pizarro y Almagro.

Garcilaso, frente a lo expuesto, defiende que las encomiendas se hereden y que los indios trabajen y afirma, además, que los españoles, en general, pagaban los trabajos de los indios y que los trataron como a hijos, así como añade que los jornaleros en España también comen de sus trabajos, cavan y siegan. En sus palabras:

Muchos hubo que les pagaban su trabajo y trataron como a hijos; y los indios también tenían y tienen hoy el cargarse por caudal suyo, que son como los jornaleros de España que comen de su trabajo, alquilándose para cavar o segar; y mandar que no se cargasen los indios también era hacerle agravio a ellos, porque les quitaban su ganancia; sino que se había de mandar que fuesen castigados severísimamente los que no los pagasen. (Garcilaso de la Vega, 1960: 213).

${ }^{8}$ El protagonismo que adquiere el demonio es muy significativo en la crónica garcilasiana y similar al que tiene en la crónica de José de Acosta. 
La ordenanza requerida por las Casas, en su opinión, quitaba el trabajo a los propios indios y su ganancia (Garcilaso de la Vega, 1960: 212). Garcilaso aprueba que se tasen los tributos y que los indios trabajen en las minas porque, de otra forma, no llevarían plata y oro a España. Anota, en cuanto al servicio personal, que los indios lo hacían de "buena gana", "con facilidad y contento" y que no querían apartarse de sus dueños, poniendo el ejemplo de Panamá donde muchos indios de servicio fueron devueltos a su tierra peruana, en contra de su voluntad. Es decir que en el intento de darles la libertad, según el Inca, se la quitaban, pues ellos no querían volver con sus caciques, al haberse hecho cristianos y, además, regresar suponía un peligro para sus vidas. Garcilaso lo demuestra con el ejemplo paterno: "Mi padre tenía tres pueblos pequeños dentro en el valle del Cozco y tenía indios a su cargo y estos estaban muy contentos".

El cronista peruano informa de las desdichas que ocasionó la implantación de las Leyes en Perú, en sus palabras, "que fueron en todo contrarias a las prosperidades y causaron daños, robos, tiranías y crueldades". Según el Inca, que sigue también a Diego Fernández "el Palentino" y a Francisco López de Gómara, el visorrey Blasco Núñez, "tan determinadamente y contra el parecer de Agustín de Zárate y de sus propios oidores, quiso ejecutar ordenanzas muy rigurosas, sin considerar cosa alguna de las que se debían mirar en puro y servicio del rey".

Garcilaso no oculta las malas opiniones que autores como Diego Fernández "el Palentino" o Francisco López de Gómara tienen de Bartolomé de las Casas, quienes comentan los tejemanejes del autor de la Brevísima para que se promulgaran las Leyes Nuevas, al mismo tiempo que señala cómo fue gracias a la prudencia del buen cardenal García de Loaysa que tales ordenanzas fueron reprendidas (Garcilaso de la Vega, 1960: 211). Asimismo, el Inca informa del encuentro poco grato que tuvo con Bartolomé de las Casas, a quien conoció en Madrid en el año de 1562: "y porque supo que yo era de Indias me dio sus manos para que se las besasse, pero cuando entendió que era del Perú y no de México, tuvo poco que hablarme".

Garcilaso reescribe las razones por las que los agraviados de la Ciudad de los Reyes, contrarios a las ordenanzas, no querían recibir al virrey Blasco Núñez: que no se pueden quitar las tierras a quienes las han conquistado; que si tras las guerras de los hermanos don Pedro el Cruel y don Enrique algún rey sucesor mandara que les quitaran todos los estados y mayorazgos a sus dueños, ¿qué harían los hombres poderosos de toda España? Y lo mismo sucedería con las guerras habidas entre Castilla y Portugal; que por la cuarta ordenanza nadie podría tener indios ni hacienda en todo Perú, pues no hay hombre que no hubiera luchado o con el bando de Pizarro o con el de Almagro.

Apoyándose en Zárate y "el Palentino", Garcilaso informa de la prisión de Vaca de Castro y de que no sólo los conquistadores estaban en desacuerdo con la aprobación de las Leyes sino también los propios oidores que "como hombres desapasionados, cuerdos y prudentes, veían que según la alteración que las ordenanzas con sólo el sonido habían causado, sería mucho mayor la que causaría la ejecución de 
ellas”. El Inca explicará el apoyo de cuatro ciudades principales para que Gonzalo Pizarro fuera procurador general de aquel Imperio, con la intención de que, desde su cargo, pudiera tratar de las ordenanzas con el Virrey Blasco Núñez. Sigue su narración con las luchas entre ellos, la prisión del visorrey por parte de los oidores (entre los que se encontraba el propio Zárate) y la huida del padre del Inca Garcilaso, junto con otros, al ver tomada la tierra por Gonzalo Pizarro.

Es evidente que la Historia general del Perú tiene, entre otros, el objetivo de defender la inocencia del padre del autor, a quien éste hace prisionero del rebelde Pizarro: "y yo digo lo que pasó como persona a quien le cupo mucha parte de aquellos trabajos y necesidades de mi padre, que en tres años no gozó de sus indios, que estuvo desposeído de ellos, en los cuales él y los suyos, que como atrás dije, éramos ocho, vivimos de limosna". El Inca transcribe en su Historia "La oración fúnebre de un religioso a la muerte de Garcilaso, mi señor", como un testimonio más de la lealtad de su padre a la Corona.

Garcilaso cuenta cómo, llegada la información sobre los terribles acontecimientos que produjeron la implantación de las Leyes Nuevas, "se creyó que pues el mal había nacido del rigor de las leyes y de la aspereza de la condición del visorrey, era bien curarle con cosas contrarias, haciendo nuevas leyes en contra de aquéllas y enviando con ellas un hombre blando, afable, suave, de prudencia, experiencia consejo, sagaz, astuto". De esta manera eligieron al licenciado Pedro de la Gasca, clérigo presbítero del consejo de la general Inquisición, que dispuso de nuevas encomiendas, si bien se opuso a que fueran hereditarias, y castigó a los seguidores de Gonzalo Pizarro. Garcilaso tiene palabras de elogio hacia La Gasca, hacia el visorrey Antonio de Mendoza, que gobernó con "suavidad y blandura" lo poco que vivió, y en general hacia los virreyes que fueron pasando por el Perú. Narra la rebelión y muerte de Francisco Hernández Girón, la llegada del marqués de Cañete, don Andrés Hurtado de Mendoza (quien echó del Perú a los seguidores de Hernández Girón y redujo al príncipe heredero Inca Sairi Túpac) y el mandato breve, en 1570, del Conde de Nieva. Con el gobierno de Francisco de Toledo, tras Lope García de Castro, pondrá fin a la crónica. De Toledo opina exactamente lo mismo que de los gobernantes anteriores, que "gobernó con suavidad y blandura", si bien explica, acto seguido, cómo determinó sacar de las montañas a Túpac Amaru y la ejecución de este. El Inca señala la crueldad y tragedia de tal muerte aunque, matiza, "puede ser que el visorrey haya tenido más razones para justificar su hecho". En el penúltimo capítulo explica, de forma muy vaga y sin entrar en materia, que Toledo extirpó y apagó la real sucesión de los Incas Reyes del Perú, que puso leyes y ordenanzas para el aumento de la hacienda real y en el beneficio de las minas de plata y del azogue ("mandó que por su vez y rueda acudiesen tantos indios de cada provincia a trabajar en las dichas minas, pagándoseles a cada uno su jornal") para regalo de los españoles. El Inca concluye en este punto su Historia, no sin aclarar las medidas tomadas por el rey Felipe II contra Toledo, por haber usurpado oro y plata de Perú y por haber matado a Túpac Amaru. 
El inca Garcilaso escribe los Comentarios reales y la Historia general del Perú con la pretensión de restituir el poder de los reyes incas del Perú, pues sus leyes, como hemos comentado, eran acordes - hasta la llegada de las Leyes Nuevas- con las de los españoles, y acata tanto la doctrina cristiana como el papel de los españoles en la labor de cristianización (la cual ya presiente Huayna Cápac en los Comentarios reales). El proyecto político del Inca es conseguir la paz entre españoles e indios, a través de un pacto por el que los primeros extiendan el cristianismo y los incas puedan restituir su imperio. Dicho proyecto político precisaba de dos móviles: el primero guarda relación con las fantasmagóricas (por inexistentes) capitulaciones que ocupan buena parte de la Historia general del Perú, un pacto entre españoles e indios ${ }^{9}$ que también se encuentra en las crónicas de Guaman Poma de Ayala o de Juan Anello Oliva; ${ }^{10}$ y el segundo móvil, con el rechazo de Garcilaso de las ideas lascasianas y de las Leyes Nuevas. Para ello, en los Comentarios reales formulará una serie de valoraciones negativas respecto de los habitantes de la primera edad garcilasiana, los preincas, y buscará conectar las enseñanzas y propósitos de la primera pareja Manco Cápac y Mama Ocllo como resultado de la piedad y disposición del dios cristiano, para que su pueblo salga del estado salvaje y se integre en la civilización y la historia. Los incas iniciarán el adoctrinamiento y la civilización del territorio que se consumará con la llegada de los españoles. En la Historia general del Perú (segunda parte de los Comentarios reales) se dibuja una época de felicidad entre indios y españoles, en la que aquellos acatan el cristianismo y en donde se siguen unas leyes conformes a los reyes incas, leyes naturales que desaparecerán con la implantación de las Leyes Nuevas y cuya repercusión será catastrófica, en opinión de Garcilaso, pues provocarán la muerte de Manco Inca, la rebelión de Gonzalo Pizarro, la acusación de traidor a su padre y la imposibilidad de restitución del imperio inca. El proyecto político del inca Garcilaso armonizaba, además, con la legislación colonial española pues no hay que olvidar que en la última disposición de las Leyes de Valladolid, de 1513, se ordena lo siguiente:

${ }^{9}$ En su Historia general del Perú, Garcilaso explica que Francisco de Chaves, en nombre de todos los españoles, fue el autor de ciertas capitulaciones de paz y amistad que los indios pidieron, siendo las más notables las siguientes: Que todas las injurias, delitos y agravios hasta entonces sucedidos de una parte se borrasen; que hubiese paz entre españoles y indios; que los españoles no contradijesen la Corona del imperio a Manco Inca porque era el legítimo heredero; que indios y españoles en sus tratos y contratos se hubiesen como amigos y que quedasen confederados para socorrerse y ayudarse unos a otros; que los españoles soltasen a los indios presos; que las leyes de los pasados Incas, hechas en beneficio de los vasallos que no fuesen contra la ley cristiana, se guardasen inviolablemente.

${ }^{10}$ El jesuita Giovanni Anello Oliva (Nápoles 1572-Lima, 1642), en su crónica Historia del reino y provincias del Perú, de 1631, retomará el tema de las "fabulosas" capitulaciones. 
Ítem, ordenamos e mandamos que dentro de dos años los hombres y las mujeres anden vestidos, y por cuanto podría acaecer que andando el tiempo con la doctrina y con la conversación de los cristianos se hagan los indios tan capaces y tan aparejados a ser cristianos y sean tan políticos y entendidos que por sí sepan regirse y tomen la manera de la vida que allá viven los cristianos, declaramos y mandamos y decimos que es nuestra voluntad que los que así se hicieren hábiles para poder vivir por sí y regirse a vista y arbitrio de nuestros jueces que ahora en la dicha isla están o estovieren de aquí adelante, que les den facultad que vivan por sí, y les manden servir en aquellas cosas que nuestros vasallos acá suelen servir o las que allá concurrieren semejantes a la calidad de las de acá, para que sirvan e paguen el servicio que los vasallos suelen dar e pagar a sus príncipes. (Leyes de Burgos, 1991: 82)

Es decir que se prevé la posibilidad de que, una vez civilizados, los indios puedan regirse por sí mismos y ser hombres sin tutela, observándose, como señala Pérez-Bustamante, "de este modo la meta ideal que en el espíritu de los Monarcas y de los Juristas y Teólogos parece informar todo este cuerpo normativo, la total y definitiva equiparación de indios y españoles como súbditos iguales de un mismo Reino" (Pérez-Bustamante, 1991: 106). Este estatus al parecer de Garcilaso lo habían alcanzado los incas, los civilizadores del Tahuantinsuyo.

Felipe Guaman Poma de Ayala (1534?-1615), nacido en San Cristóbal de Suntunto (Sondondo), región de Huanuco o Lucanas, se proclamará heredero de dos tradiciones reales del Perú prehispánico: los incas y los yarovilcas. Su madre fue Juana Curi Ocllo, hija menor del décimo inca Túpac Yupanqui; su padre, Martín de Ayala, desciende de los yarovilca allauca huánucos que dominaban el Chinchaysuyo y lograron la unidad imperial antes que los incas. ${ }^{11}$ Su nombre se configura dentro de la bipolaridad hanan-hurin, de tal manera que el halcón del mundo de arriba se une al puma del mundo de abajo. Su Nueva corónica y buen gobierno anduvo perdida hasta que en 1909 fue descubierta en Copenhague. El manuscrito, versión final de un borrador de Guaman, posee 1.188 folios. Su elaboración abarca un periodo de pocos años, frente a los 20 o 30 que dice su autor haber investigado. La primera parte de su obra, la Nueva corónica, fue escrita entre 1612 y 1613 , y la segunda, el Buen gobierno, entre 1613 y 1614.

${ }^{11}$ Sobre los problemas biográficos que genera la personalidad de Guaman, con numerosos episodios dudosos, debe consultarse el estudio de Raúl Porras Barrenechea, Indagaciones peruanas. El legado quechua, en Obras completas de Raúl Porras Barrenechea, Lima, Universidad Nacional Mayor de San Marcos, 1999. Según Porras, que biografía al cronista indio ladino, este pasaría la infancia en Cuzco y su peregrinaje sería más corto del que se ha dado por cierto, pues su vida transcurriría íntegramente en las provincias de Huamanga, con algún que otro viaje a Lima, desconociendo las dos terceras partes del Perú. 
Dividida en dos partes, la primera es la historia del Tahuantinsuyo, que comienza con la creación del mundo por Dios y termina con la conquista de Perú y las guerras civiles. La visión que ofrece el autor del incario es negativa y opuesta a la de Garcilaso de la Vega, por entender que dicho régimen es ilegítimo, despótico y cruel, por lo que la llegada de los españoles, no siendo buena, sí que supondrá el fin de las idolatrías. ${ }^{12}$ La segunda parte, el "Buen gobierno", es la relación de la historia de los primeros años del siglo XVII, principalmente de 1608 a 1613, y describe la vida de los indios en el régimen colonial. Se trata, en concreto, de un memorial de quejas y protestas, un alegato dirigido al rey de España, para mostrarle el presente y el pasado del Perú, sus males y sus soluciones. En aras a un buen gobierno, denuncia los abusos de los españoles, la idolatría de los indios, la codicia de los caciques y la lujuria de los clérigos y alaba al rey y a ciertas autoridades. No hay que olvidar que el padre de Guaman recibió gratamente a Pizarro y Almagro porque eran los representantes del rey.

Guaman, que se presenta como consejero real, denuncia, en primer lugar, a los corregidores, ${ }^{13}$ seguidos de los curas (exime a los franciscanos y jesuitas), encomenderos y falsos licenciados, arremete contra la haraganería del criollo ("peores que mestizos, mulatos y negros"), y critica al virrey de Toledo que se atrevió a usurpar el rol de inca, legítimamente traspasado por Huáscar a Felipe III, y que ajustició, atribuyéndose una potestad de la que carecía, a Túpac Amaru, iniciando el mal gobierno. Guaman acusa a los negros y a los incas de haber impuesto la idolatría. La conquista española, además, trajo las mezclas sociales y raciales y desmanteló las estructuras jerárquicas de los indios -las cuales representaban, paradójicamente, el buen gobierno- que desestabilizaron al Perú.

Nuestro cronista indio dedica un "Capítulo de encomenderos", en la parte del Buen gobierno, a explicar el funcionamiento del sistema de las encomiendas y su aplicación en el Perú. Frente a Garcilaso de la Vega, critica las encomiendas por el abuso que los encomenderos perpetran contra los indios, a los cuales no les pagan, les explotan, les quitan la hacienda, les roban la mujer y las hijas y les esclavizan. Al no poder los indios, con solo su trabajo, cumplir con el tributo, tienen que hacerlo con los productos de sus propias chacras. Cumplir con la mita significaba que el indio debía trabajar siete u ocho meses al año. Además, como muchos morían, los que quedaban vivos debían tributar aún más. Guaman se dirige a los malos cristianos, guiados por Lucifer:

${ }^{12}$ No es el tema de nuestro artículo y por tanto no recogemos los orígenes míticos, la época arcádica en la que Guaman cree y busca construir las bases de un origen común y de naturaleza ecuménica, y que parte de los Uari Uiracocha runas y sus descendientes.

${ }^{13}$ Los corregidores fueron, al ser los que tenían más poder, los que abusaron y cometieron mayores atropellos contra los indios, de manera que se dictaron varias ordenanzas para frenar su poder, si bien fueron inútiles. 
Llegando a las estancias de los pobres indios, luego les robáis sus ganados y comidas y costales [...] y si podéis le quitáis plata, y lo hacéis trabajar en balde, y en los dichos tambos no le pagáis de sus trabajos y sudores, y jornales, y de las comidas, y de otras especias, de todo ello no teméis a Dios ni a la justicia, y en los caminos sois tan señor absoluto y le dais a los indios mitayos de palos como a bestia, y le hacéis cargas como animal [...]. (Guaman Poma de Ayala, 1980, I : 418)

Franklin Pease sugiere, en el tema de la implantación del régimen colonial, que Guaman se acerca a los esquemas toledanos, ${ }^{14}$ por cuanto la invasión española destruía un régimen ilegítimo, el de Atahualpa, frente al legítimo, guiado por Huáscar (Guaman Poma de Ayala, 1980, I: LIII), en afinidad a la línea garcilasiana. Pero "los toledanos, aproximadamente cuarenta años después de Cajamarca, exhumaron la imagen clamando por la ilegitimidad de todos los incas; Poma ingresa también dentro de este criterio", según Pease.

Guaman $^{15}$ alude también al supuesto pacto, en 1532, entre indios y españoles llevado a cabo por un embajador de Huáscar y por Francisco Pizarro- de entrega del Tahuantinsuyo al rey de España, tras la muerte de Huayna Cápac, si bien Porras Barrenechea ya habló de la falsedad de tales hechos históricos. En cualquier caso, el supuesto pacto en el que se apoya Guaman conllevaría la idea de que no hubo guerra de conquista, tesis que sostiene el Inca Garcilaso al dibujar en su Historia general del Perú un clima de paz entre unos y otros hasta la llegada de las Leyes Nuevas.

Guaman empleará, por tanto, el argumento de que no hubo guerra (aunque se contradirá al tratar sobre los hechos previos a la muerte de Atahualpa) para formular

${ }^{14}$ Porras Barrenechea señala, asimismo, que, en contra de lo que se ha venido diciendo en torno a que Guaman se alza para defender a los incas de la acusación de tiranía que les hicieron las Informaciones de Toledo, la lectura de la Nueva corónica produce la impresión de que el autor se suma, en representación de los pueblos del Chinchaysuyo, vencidos por los incas, a las más graves acusaciones dirigidas por los cronistas toledanos contra el Incario (Porras Barrenechea, 1999: 88)

15 “Año de mil quinientos treinta y dos, papa Clemente siete, de su pontificado diez, emperador Carlos cinco de su imperio catorce y de su reinado quince, don Felipe Pizarro y don Diego de Almagro tuvieron el primer embajador del legítimo y rey Cápac Apo Inga Topa Cusi Gualpa Uáscar Inga, rey y señor de este reino, le envió a dar paz al puerto de Tumbes al embajador del emperador y rey de Castilla, le envió a su segunda persona, virrey de este reino, Cápac Apo excelentísimo señor don Martín Guaman Malqui de Ayala, fue embajador de la gran ciudad del Cuzco cabecera de este reino, y los españoles don Francisco Pizarro y don Diego Almagro y don Martín de Ayala se hincaron de rodillas y se abrazaron y se dieron paz, amistad, con el emperador, y le honró y comió en su mesa, y hablar y conversaron, y le dio presentes a los cristianos, así mismo le dio al señor don Martín de Ayala que fue primer embajador que de Atahualpa Inga en el puerto de Tumbes a donde saltó primero" (Guaman Poma de Ayala, 1980: 275) 
la idea de que fueron los españoles los que, olvidando dicho pacto, y por su soberbia, obraron mal y para negar las atribuciones de los encomenderos:

Los dichos encomenderos no se pueden llamarse encomenderos de indios ni conquistadores por derecho de justicia, porque no fue conquistador de los indios, sino que de buena voluntad se dio de paz a la corona real sin alzamiento, como los primeros infantes y señores príncipes y principales grandes de este reino fueron al puerto de Tumbes [...] y así, no tenemos encomendero ni conquistador sino que somos de la corona real de Su Majestad, servicio de Dios y de su corona. (Guaman Poma de Ayala,1980, I : 421)

Francisco de Toledo, entre 1568 y 1581, impuso, entre otras medidas que atañían a la política eclesiástica -intensificar la labor evangelizadora, vigilar la salud espiritual de los indios o corregir los desmanes de los clérigos-, las reducciones de los indios a pueblos, siguiendo las primeras disposiciones de la justicia colonial efectuadas por la reina Isabel, tras ser informada de la falta de comunicación entre unos y otros y de la imposibilidad de la evangelización. Guaman criticará no solo el régimen de las encomiendas sino el de las reducciones. En concreto, señala que Toledo mandó reducir y poblar el Perú y en el Cuzco, "adonde hizo reducir y poblar a los indios, algunos en buena parte, algunos en mala parte, como la suerte cayó; y por ello se desbarataron los indios de su querencia por tener sementeras muy lejos, y tienen los indios" (Guaman Poma de Ayala, 1980, I: 329).

Guaman critica asimismo que las ordenanzas de Toledo -el cual se valió de las informaciones de Polo de Ondegardo, Acosta y otros cronistas- llevaron a la despoblación de las tierras andinas. Este abandono motivó la caída del sistema de las encomiendas, pues los encomenderos se hicieron con las tierras deshabitadas y se dedicaron a otras actividades. Pero Guaman da por buenas otras ordenanzas de Toledo, como "que ningún vecino encomendero de indios ni entrase ni español, ni mestizo, ni mulato, ni negro, en sus pueblos ni tierras sino en sus términos sino que fuesen a las ciudades a vivir ellos" (Guaman, 1980, I: 330), para evitar daños y males entre los indios, es decir que estos vivieran en su comunidad separados de los blancos, mestizos, negros o mulatos. Asimismo, suscribe la ordenanza toledana por la que ni "los corregidores, ni padres de las dotrinas ni encomenderos, ni ningún español no les ocupasen a los pobres indios a ningún trabajo sino de que trabajasen en sus haciendas los indios, y en su tributo lo que eran obligados el indio mozo" (Guaman, 1980, I: 331).

Guaman celebra también la ordenanza toledana que reestablecía algunas costumbres de los indios, como la de que "comiesen en público plaza, y la fiesta también" (Guaman, 1980, I: 331). El cronista indio sugiere, de este modo, que la comunidad viva de acuerdo con sus costumbres ancestrales.

Guaman, entre otras reformas, expuso la petición de que el trabajo girara alrededor de la minga y que el indio no trabajara ni en la casa ni en las chacras de los 
blancos. También propuso la devolución de las tierras confiscadas a sus legítimos dueños, los indios: "Es muy justo que se vuelvan y restituyan las dichas tierras y corrales y pastos que se vendieron en nombre de Su Majestad porque debajo de conciencia no se le puede quitársele a los naturales legítimos propietarios de las dichas tierras", y que estos las alquilen o arriende a los españoles o mestizos o negros y "paguen un tanto al dicho dueño. Y el dicho dueño de ello pague el quinto a su Majestad" (Guaman, 1980, I: 402). Cabe aclarar que cuando Guaman demanda que se devuelvan las tierras a sus antiguos dueños, se refiere a los antepasados, no a los incas.

En los cambios que formula nuestro autor, el trabajo del indio solo sería supervisado por los verdaderos curacas, los del linaje, no por los falsos corregidores, encomenderos, curas o españoles. (Guaman, 1980, I: 362). Sobre las minas (Guaman, 1980, I: 398 y ss.), plantea que a ellas vayan los más fuertes, que sólo una vez en la vida entren en los hornos de azogue -"que en las dichas minas de azogue los indios que entraren, al socavón de cualquiera mina, un indio un día, no entre más hasta que se vaya, asimismo al horno del azogue" (Guaman, 1980, I: 396) -, y que alternen un día de trabajo con otro de descanso. Sugiere en estas reformas, que tienen como finalidad la protección exclusivamente de los indios sobre las demás razas, una ampliación de la base tributaría por la que el mestizo, zambo, cholo, mulato o los horros paguen tributos y hagan servicio personal.

Guaman alabará las ordenanzas de Túpac Inca Yupanqui por su alto nivel de organización. Aspira a un régimen de trabajo como el del incario, basado en un sistema de reciprocidad en el que los indios tributaban trabajando para el Estado, para la comunidad y para sí mismos y en el que, en tiempo de escasez, el Inca ayudaba al pueblo con lo acumulado. Guaman aprueba que Toledo, en sus ordenanzas, haya dispuesto que el tributo del indio revierta en su propio "sapci" o bien comunal.

Guaman defiende la transferencia pacífica de la soberanía en los Andes. En definitiva, idea un estado soberano andino, formado por cuatro reyes: indio, turco, negro y romano o europeo, pide la restauración de los curacas, la eliminación del corregidor o encomendero y defiende un gobierno de casta (curacas legítimos) unido al del rey de Europa.

\section{Conclusión}

Las obras de Garcilaso de la Vega y de Guaman Poma de Ayala reivindican una cosmovisión americana aliada a una visión cristiana occidental, pero las valoraciones de ambos cronistas responden a objetivos totalmente divergentes. Para Garcilaso, son los incas los que realizan una función mesiánica y civilizadora; para Guaman son los Uari Uaricocha runas los civilizados. Dichos antepasados preincaicos fueron monoteístas, precristianos y sólo la idolatría de los incas hizo que se abandonara el conocimiento de Dios por las huacas o deidades telúricas. De ahí la justi- 
ficación teleológica de la llegada de los españoles, necesaria para la restauración de la fe en el Perú. No obstante, los abusos cometidos por los españoles que niegan el cristianismo harán que Guaman proponga un retorno a la edad de oro del tiempo primordial andino, monoteísta, precristiano y civilizador. Para Garcilaso, por el contrario, los incas, monoteístas y prefiguradores del cristianismo, allanarán el camino a los españoles, quienes serán los encargados de completar la tarea civilizadora.

En ambos cronistas, el imperio español es instrumento de los designios divinos y la conquista es aceptada, pues responde o forma parte de un proceso legitimado por la autoridad del Dios cristiano, que en América cobra forma en la persona del Rey. Los dos se apoyan en la sociedad de casta o linaje y aceptan el sistema de las encomiendas, en el caso específico de Guaman dependiendo del sujeto al que se apliquen. La propuesta política de Guaman (más allá del intento de favorecerse en virtud de ciertos privilegios de clase) es devolver el poder a los caciques de linaje (estos sí pueden tener encomiendas) y arrebatárselo a los caciques indios que son usurpadores, cómplices del corregidor e indios bajos; la propuesta de Garcilaso es la de restituir el poder de los incas. Uno y otro proclaman la soberanía de los Andes, lo cual se ajustaba o, al menos, no chocaba frontalmente con las leyes coloniales, pues en una ordenanza de las Leyes de Valladolid se dejaba abierta la posibilidad de que los indios podrían ser hombres libres y regirse por sí mismos, una vez que estuvieran civilizados y no precisaran de la tutela de los españoles. Según Guaman, los pueblos andinos y, según Garcilaso, los incas, ya vivían como cristianos y por tanto habían alcanzado dicho status de autonomía.

\section{BIBLIOGRAFÍA}

ADORNO, Rolena.

1992 Cronista y príncipe: La obra de don Felipe Guaman Poma de Ayala. Lima: Fondo Editorial de la Pontificia Universidad Católica del Perú.

Colección de documentos inéditos relativos al descubrimiento, conquista y organización de las antiguas posesiones españolas en América y Oceanía, sacados en su mayor parte del Real Archivo de Indias. Madrid: Imprenta M. Bernaldo de Quirós, 1864-1884, 42 vols.

CHANG-RODRÍGUEZ, Raquel.

2005 La palabra y la pluma en Primer y nueva corónica y buen gobierno. Lima: Fondo Editorial de la Pontificia Universidad Católica del Perú.

ESCALANTE ADANIYA, Marie Elise.

2004 Un estudio sobre la nominación en las crónicas de Garcilaso de la Vega y Guaman Poma. Lima: Fondo Editorial de la Universidad Nacional Mayor de San Marcos. 
FERNÁNDEZ DE OVIEDO, Gonzalo.

1959 Historia general y natural de las Indias, edición y estudio de Juan Pérez de Tudela. Madrid: B.A.E., vol. 119.

FERNÁNDEZ DE NAVARRETE, Martín.

1825 Colección de los viajes y descubrimientos que hicieron por mar los españoles, desde fines del siglo XV. Madrid: Imprenta Real.

GARCÍA CASTELLÓN, Manuel.

1992 Guaman Poma de Ayala, pionero de la teología de la liberación. Madrid: Editorial Pliegos.

GARCILASO DE LA VEGA, Inca.

1944 Historia general del Perú (segunda parte de los Comentarios Reales de los Incas). Ed. al cuidado de Ángel Rosenblat, elogio del autor y examen de la segunda parte de los Comentarios Reales por José de la Riva Agüero. Buenos Aires: Emecé Editores, tres tomos.

1960 Historia general del Perú. Madrid: Biblioteca de Autores Españoles.

2000 Comentarios reales. Ed. de Mercedes Serna Arnaiz. Madrid: Castalia.

HAMPE, Teodoro.

1991 "Agustín de Zárate, contador y cronista indiano", Revista Mélanges de la Casa de Velázquez, vol. 27, n 27-2.

KLAUER, Alfonso.

2005 En las garras del imperio. Descubrimiento y conquista. Ed. electrónica a texto completo en www.eumed.net/libros/2005/ak4/

Leyes de Burgos de 1512 y Leyes de Valladolid de 1513. Reproducción facsimilar de los manuscritos que se conservan en el Archivo General de Indias (Sevilla) en las secciones de indiferente general Leg. 419, lib. IV y patronato, legajo 174 Ramo 1, respectivamente, análisis histórico y transcripción paleográfica por María Luisa Martínez de Salinas, estudio jurídico institucional por Rogelio Pérez-Bustamante. Burgos: Egeria Fundación para el desarrollo provincial, 1991, pp. 57-82.

LÓPEZ-BARALT, Mercedes.

1988 Icono y conquista: Guamán Poma de Ayala. Madrid: Hiperión.

1993 Guaman Poma, autor y artista. Lima: Fondo Editorial de la Pontificia Universidad Católica del Perú.

MATICORENA, Miguel.

1992 "Una carta sobre el Inca Garcilaso", El Comercio, 26 de abril, Lima.

PEREÑA, Luciano.

1992 La idea de justicia en la conquista de América. Madrid: MAPFRE. 
PÉREZ-BustamanTE, Rogelio

1991 "Las Leyes de Burgos de 1512. Estudio jurídico e Institucional", en Leyes de Burgos de 1512. Burgos.

PÉREZ DE TUDELA, Juan (ed.).

1958 Opúsculos, cartas y memoriales. Obras recogidas de fray Bartolomé de las Casas. Madrid: BAE (CX)-Atlas.

POMA DE AYALA, Guaman.

1980 Nueva corónica y buen gobierno. Transcripción, pról., notas y cronología de Franklin Pease. Caracas: Biblioteca Ayacucho, vols. 75 y 76.

PORRAS BARRENECHEA, Raúl.

1962 Los cronistas del Perú y otros ensayos. Lima: Sanmartí Impresores.

1999 Indagaciones peruanas. El legado quechua, en Obras completas de Raúl Porras Barrenechea. Lima: Universidad Nacional Mayor de San Marcos.

QUISPE AGNOLI, Rocío.

2006 La fe andina en la escritura: resistencia e identidad en la obra de Guaman Poma de Ayala. Lima: Fondo editorial de la Universidad Nacional Mayor de San Marco.

SOMEDA, Hidefuji.

2005 Apología e historia. Lima: Pontificia Universidad Católica del Perú.

ZAVALA, Silvio.

1947 Filosofia de la conquista. México: FCE.

1971 Las instituciones jurídicas en la conquista de América. México: Porrúa.

1973 La encomienda indiana. México: Porrúa.

1991 Repaso histórico de la Bula Sublimis Deus de Paulo III en defensa de los indios. México: Universidad Iberoamericana. 